\title{
Research on the Network Marketing Strategy of the Ancient City of Taierzhuang
}

\author{
Jianyong Bai ${ }^{1, a}$, Jianli Han ${ }^{1, b}$
}

${ }^{1}$ School of Economics and Management, Zaozhuang University, Zaozhuang 277160, China.

a157003974@qq.com, b165698650@qq.com

\begin{abstract}
The ancient city of Taierzhuang is located in the southeast of Zaozhuang, Shandong Province. Taierzhuang lies in the Grand Canal from Beijing to Hangzhou. The ancient city of Taierzhuang is the most preserved ancient river. In recent years, the number of tourists in the ancient city of Taierzhuang has increased rapidly. In 2017, the total number of visitors to Taierzhuang was 5 million 818 thousand and 600 person times. The business income of Taierzhuang is 347 million yuan. Taierzhuang's offline tourism market is hot, but there are some problems in the promotion of Taierzhuang's ancient city network. For example, the function of the website construction is not perfect, the Mobile APP promotion is unfavorable and the construction of interactive facilities is not perfect. Therefore, this paper puts forward corresponding suggestions for improving these problems, which will help Taierzhuang's ancient city development.
\end{abstract}

Keywords: Ancient city of Taierzhuang; network marketing; network promotion; website construction.

\section{台儿庄古城网络营销策略研究}

\section{白建勇 ${ }^{1}$, 韩建丽 ${ }^{1}$}

${ }^{1}$ 丰庄学院经济与管理学院, 菄庄 中国

摘 要: 台儿庄古城坐落于山东零庄市东南, 处于京杭大运河的中心点, 是目前保存最为完整 的古运河段。近几年来, 台儿庄古城旅游人数快速增长, 2017年台儿庄古城全年游客接待量 为581. 86 万人次, 营业收入 3.47 亿元, 相对于线下旅游市场的火热, 台儿庄古城的网络推广 方面却存在一些问题, 如网站建设的功能不完善、移动APP推广不利、互动设施构建不完善等。 所以本文以此为研究内容, 针对这些问题提出相改进建议, 为台儿庄古城的发展提供助力。

关键词：台儿庄古城；网络营销；网络推广；网站建设

\section{1. 前言}

旅游业作为 “永恒的朝阳产业” 和 “无烟产业” ，已逐渐成为提高 GDP 的重要指标。近 年来，中国的旅游业迅速崛起，2017 年我国实现旅游总收入 5.4 万亿元，增长 $15.1 \%$, 全年 全国旅游业对 GDP 的综合贡献为 9.13 万亿元，占 GDP 总量的 $11.04 \%$, 所以中国的旅游经济 仍有广阔的发展前景。

台儿庄古城位于山东省南部，是国家 $5 \mathrm{~A}$ 级旅游景区，被世界旅游组织称为 “活着的古运 河”、“京杭运河仅存的遗产村落”。它形成于汉，发展于元，繁荣于明清，因运河而兴，因 大战废墟。台儿庄古城内有古河道、古船埠、中华古水城、海峡两岸交流基地、台儿庄大战 纪念馆，与波兰首都华沙同属世界上仅存在的两座因第二次世界大战炮火损毁而作为世界文 化遗产重修的城市。台儿庄古城依托丰富的大战文化、运河文化、鲁南民俗文化等文化资源， 进一步加快运河文明的建设。优越的地理位置, 丰富的历史文化, 充足的旅游价值为台儿庄 的旅游网络营销提供了良好的基础条件。

2017 年台儿庄古城全年游客接待量为 581.86 万人次，营业收入 3.47 亿元，同比分别增 长 $15.8 \% 、 37.6 \%$ 。相对于线下市场的火爆, 线上旅游市场却相对冷清, 如何制定适合自身的 旅游营销策略, 如何在激烈的市场竞争中抢占先机展现自身的优势, 成为台儿庄古城旅游网 
络营销迫在眉睫的问题。本文旨在通过对台儿庄古城的网络营销现状研究的基础上, 总结国 内外 $5 \mathrm{~A}$ 级景区的网络营销策略的成功经验, 为台儿庄古城的在线旅游市场提供相应的发展思 路, 进一步提升台儿庄古城的市场竞争力。

\section{2. 台儿庄古城旅游网络营销策略现状}

2008年，苯庄市正式宣布，重建台儿庄古城，台儿庄地处南北过渡带，落差大，又是明 清时代华东地区唯一的煤炭供应地、最大的瓜果集散地和最发达的民间制陶基地, 徽商、晋 商、浙商、闽商、粤商等各路商贾纷纷云集于此, 带来了不同的文化, 鲁南文化、江南文化、 宗教文化、运河文化、商贸文化、民俗文化等在此交汇生长，形成了三千里运河沿线独有的 南北交融、中西合璧的鲜明文化特征，文化的复合性十分明显。2012年台儿庄古城被评为国 家 $5 \mathrm{~A}$ 级旅游景区, 被美国有线电视新闻网评为 “中国最美水乡”之一。台儿庄古城自运营以 来至2017年底, 游客接待量近 3000 万人次。

近年来, 菄庄市结合资源枯竭城市的转型, 对台儿庄的历史文化进行了深入挖掘, 并依 托其独特的历史文化价值, 精心打造了台儿庄古城, 将其作为㫫庄市文化旅游业发展的龙头 和 “江北水乡、运河古城” 城市名片的核心景区并对其进行了广泛的网络营销。目前台儿庄 古城网络营销的现状主要体现在以下几个方面。

\section{1. 网站营销}

门户网站是网络用户在互联网上直接了解一个组织的最便捷的渠道。长远而言, 网站就 是实体企业在虚拟网络上的 “实体商店”，是企业线上的门面。

台儿庄古城作为京杭大运河 (山东段) 的特色景区, 是中国旅游景区中相对优秀的景区 之一, 网址为http://www.tezgc.com/, 台儿庄古城的网站可以通过百度、谷歌、360搜索等多 个搜索引擎链接，方便用户以最简单的方式获得台儿庄古城的各种信息。

\section{2. 微博营销}

微博是一个基于用户关系信息分享、传播以及获取的平台, 更注重时效性与随意性。用 户通过微博随时随地都可以表达自己的思想和最新动态，时效性更强、互动性更大。

台儿庄古城通过名为 “台儿庄古城” 微博平台, 可以提高自身的获利形象变得 “亲 切”、“可爱” , 并且在微博上可以将每一个粉丝都当作潜在营销对象, 通过实时更新微 博, 向广大消费者传播关于台儿庄运河古城的信息、历史文化知识和趣闻趣事, 并在元旦、 新年、端午等中国传统节日发布相关传统文化小知识, 在宣传的同时又达到了教育大众的目 的, 达到了聚拢公众, 树立运河古城的形象的作用。

\section{3. APP 营销}

随着网络的发展和智能手机的普及, 手机已经成为生活中必不可少的用品了。对于年轻 人来说, 最多用的无非就是淘宝、美团等, 很少有人会专门在手机里下载一个关于旅游的 APP, 台儿庄运河古城入驻了携程旅游、途牛旅游、美团、淘宝等手机APP。当你想要出门 旅游时, 打开美团, 不仅能找到台儿庄运河古城的旅游套餐, 甚至能直接预定住宿, 帮助游 客合理规划行程, 这样不仅方便了消费者的出行, 而且可以预留出更多的时间进行游览, 保 证游客有个满意的出行体验。

\section{4. 搜索引擎营销}

在网站上对台儿庄运河古城进行网站进入途径分析时发现，大多数访问者通过 “百度” 搜索引擎进入台儿庄运河古城官方网站。在百度搜索栏中输入台儿庄运河古城出现相关结果 约 179 万个, 然而在搜索台儿庄古城时, 古城的网站并没有出现在首页的位置, 大大降低了 
游客官网的访问量。从百度百科搜索结果来看, 网络用户的问题主要集中在 “台儿庄运河古 城的位置”、“台儿庄运河古城好玩吗” 以及 “台儿庄运河古城有什么好玩的” 等方面, 所 以在突出台儿庄网站官网方面和百度百科的提问方面，台儿庄古城应该下些功夫。

\section{3. 台儿庄古城网络营销策略存在问题}

虽然近几年古城在网络营销上取得了一些成绩, 打响了知名度的第一战, 但是面对越来 越多的竞争, 怎么样能够保持自己的优势, 吸收别人的经验也十分重要。只有正确面对自己 存在的问题和与其他景区的差距, 才能更好的进行改进。下面就台儿庄古城旅游网路营销存 在的问题进行分析。

\section{1. 网站建设功能不完善}

首先网站的景区特色呈现不明显。景区网站设计应与景区景点特色紧密联系，呈现网站 特色。古城网站首页除了台儿庄古城的图片之外就是一些景区介绍, 首页所呈现的五张图片 中并没有反映古城的特色, 并没有使游客能够一眼被吸引住, 再加上古城的网页大量的图文 分离, 游客很难能够将图片与文字进行结合, 这样就很难能够在头脑中形成一个动态的景 点, 影响游客对景点的进一步了解。

其次是网站内容的时效性也不是很好，台儿庄古城网站的文字介绍大都停滞在2017年， 2018年的网站内容没有得到更新, 这样会降低游客对台儿庄古城的信任度和好感度, 有可能 导致在线游客的丢失。

最后是在线旅游功能缺失。目前国内的一些景区网站已经有了虚拟旅游的板块。如故宫 的紫禁城、南京的中山陵已经符合虚拟旅游的基本标准, 给人身临其境的感受。但台儿庄运 河古城还没有虚拟旅游这一概念, 没有建立虚拟旅游板块, 没有能够让顾客在到达这里之前 先感受一些这里美丽的风景, 美好的景色。

\section{2. 移动 APP 推广不利}

在APP推广方面, 一方面台儿庄古城没有自己的移动APP, 对于大量的手机移动用户而 言, 无法通过手机APP来了解台儿庄古城和购买门票, 这样会导致部分手机用户无法对其有 足够的了解。另一方面在携程旅游、途牛旅游、美团、淘宝等APP中, 台儿庄古城的图文介 绍并没有能够完美的展示古城的景色, 致使台儿庄古城很难在众多的 $5 \mathrm{~A}$ 级景点中脱颖而出, 所以加强APP的推广方面刻不容缓。

在携程旅游、途牛旅游、美团、淘宝等APP中订票的客户, 在旅游结束时, 会对旅游的 感受进行评分和评价, 而这个评分就关系到景区在APP中的排名, 但是观察上述几个APP发现 游客在游览台儿庄古城之后在进行评价的, 台儿庄古城工作人员大都没有进行及时的回复, 甚至对有些抱怨也没有任何回复, 这就会加大游客对景区的不满, 影响APP用户对台儿庄古 城的整体评价和印象。

\section{3. 互动设施建设不完善}

虽然台儿庄古城有自己的微博, 但是却很少见到古城在微博上进行营销, 在微博搜索台 儿庄古城时, 台儿庄古城的官方竟然只排在了第二位, 点评人数和发博人数远远都不及第一 位, 在这种情况下, 面对恶性评价古城方面根本无力反驳。在微信方面, 关注了台儿庄古城 微信公众号时发现, 古城的微信公众号与多数 $5 \mathrm{~A}$ 级旅游景区并没有什么不同。关注公众号之 后, 系统会发出办卡优惠的活动, 此外只有少量的旅游攻略, 微信总体内容偏少, 更新较 慢。

在百度搜索台儿庄古城的时候, 台儿庄古城的网站不仅没有出现在前三的位置, 甚至没 有出现在第一页, 这就给游客想要了解古城带来了很大的麻烦, 很多游客有可能访问一些虚 
假网站, 而对台儿庄古城产生了错误的认识, 进入影响了去台儿庄古城旅游的积极性, 最终 导致游客的流失，所以台儿庄古城应该加大对搜索引擎的重视。

\section{4. 台儿庄古城网络营销策略的改进建议}

旅游网络营销策略的制定和选择，依靠完善的景区网络营销经营管理体制。借鉴众多国 内外知名旅游景区的网络营销策略, 针对台儿庄古城旅游网络营销策略存在的不足, 提出相 应的改进建议。

\section{1. 全面完善网站功能}

在完善网站的功能方面, 最重要的就是套突显景区的特色和内涵, 让游客一旦进入网 站, 就被眼前的美景所吸引。而且网站提供的信息必须是丰富和及时的, 让游客感受到古城 四季有不同的美感, 痴心于古城的优美景色, 大大增加了游客到访的概率。另外网站还可以 提供完备的会员注册、升级、打折制度，使会员享受到更多的优惠。

其次是定期更新网站内容, 定期发布台儿庄古城的新闻和相关报道，这样做不仅能给游 客一个好印象, 让游客感受到台儿庄古城是一个热闹的、非去不可的景点, 增加顾客对台儿 庄古城的信任感和关注度; 另一方面可以提高网站的在搜索引擎中的排名, 提高网站的访客 数, 最终提高台儿庄的实际游客数量。

最后在网站首页在网站中安插一些辅助设施, 如全文检索, 景区地图, 路线查询等。适 当运用动态导游图、虚拟旅游等, 虚拟旅游可以极大丰富旅游信息的传递, 让游客可以事先 体验旅游地, 在获得感知后, 产生实地游览的动机。

\section{2. 加强移动 $\mathrm{APP}$ 推广能力}

目前国内的 5 A级景区尚未出现有自己专门APP的，此时古城建设自己的APP，就会成为引 起广泛的关注, 而且还能拥有自己的管理权, 可以随时随地通过APP观察有多少消费者, 并 且能够及时解决消费者所提出的问题, 在管理方面很自由。另外可以在一些APP应用网站上 推出安装提供多少元的减免服务, 引发广大消费者对台儿庄古城APP的下载。

现在手机上必备的APP就是美团、淘宝和携程旅游，在这几大手机软件中加入运河古城 的旅游景点, 可以大大的提升古城的知名度。选择最能体现古城特色的图片, 将其与文案整 理起来, 投入旅游APP中, 让消费者在打开APP的时候就能看到这些展示, 能被吸引其中, 做 出选择到这里旅游的决定。

\section{3. 加强互动设施建设}

微博是常用的社交软件, 对于古城微博的关注者大多都是喜欢旅游并且有意向去古城旅 游的消费者。这个时候, 就要加强和 “粉丝” 之间的互动和沟通交流了, 首先要在微博上及 时更新古城旅游的相关优惠和信息, 其次要及时的回复网友的评论以及提出的问题, 最后可 以设置一些微博抽奖活动, 随机从评论的人中抽取人员赠送台儿庄古城门票。微信同样可以 起到互动的作用, 利用微信官方公众号可以反映古城举办了哪些活动, 有多少参加、发生了 哪些趣事, 以及网友对这件事的看法和回复, 大大增加了与游客的交流互动功能, 如微信转 发点赞就可以领取门票活动可以激发了游客对台儿庄古城的向往。

在百度搜索引擎推广方面，通过关键字排名和搜索引擎优化等方式保证游客在搜索台儿 庄古城时出现在首页上靠前的位置, 这样才能有效的增加网站的汶览量, 进而增加网站的实 际访客数, 大大提高台儿庄古城网站的知名度。 


\section{5. 总结}

随着具互联网在全球范围内的快速发展, 人类社会生活已经进入网络时代。在旅游业发 展的新形势下，台儿庄古城必须更多地借助网络营销手段，来提高自己的知名度和游客人 数。但是目前台儿庄古城网络营销还处于初级阶段, 网络推广方面存在着很多问题如网站 建设功能不完善、移动APP推广不利、互动设施建设不完善等问题, 本文针对这些问题提出 了加强网站图文管理、虚拟旅游, 移动APP方面可以投资自己的APP或者加强和其他APP的合 作, 加强微博、微信等互动设施的建设。希望这些建议能够对台儿庄古城的发展起到一定的 促进作用。

\section{References}

[1]. Philip, Kotler. Marketing management: analysis, planning and control [M]. Shanghai: Shanghai people's press, 1999.p.420-453.

[2]. Gao Xuedong. The marketing strategy on the ancient city scenic areas of Taierzhuang [D]. Shandong University, 2016.p.50-57. 